\title{
Care for hospitalized patients with unhealthy alcohol use: a narrative review
}

\author{
Regina Makdissi and Scott H Stewart ${ }^{*}$
}

\begin{abstract}
There is increasing emphasis on screening, brief intervention, and referral to treatment (SBIRT) for unhealthy alcohol use in the general hospital, as highlighted by new Joint Commission recommendations on SBIRT. However, the evidence supporting this approach is not as robust relative to primary care settings. This review is targeted to hospital-based clinicians and administrators who are responsible for generally ensuring the provision of high quality care to patients presenting with a myriad of conditions, one of which is unhealthy alcohol use. The review summarizes the major issues involved in caring for patients with unhealthy alcohol use in the general hospital setting, including prevalence, detection, assessment of severity, reduction in drinking with brief intervention, common acute management scenarios for heavy drinkers, and discharge planning. The review concludes with consideration of Joint Commission recommendations on SBIRT for unhealthy alcohol use, integration of these recommendations into hospital work flows, and directions for future research.
\end{abstract}

Keywords: Alcohol drinking, Alcoholism, Hospitalization, Patient discharge

\section{Background}

Alcohol-related problems constitute a tremendous economic and health cost in many countries throughout the world [1,2]. Screening, brief intervention, and referral to treatment (SBIRT) has become one of the major tools used to combat these problems, and is widely recommended for use in primary care by governments and expert panels $[3,4]$. Recently, the Joint Commission on Accreditation for Health Care Organizations (JCAHO), the major accrediting body for hospitals in the US, has advanced SBIRT as a quality indicator for general hospital care [5]. There is no doubt that alcohol problems are a critical issue in hospital care, but there are concerns that the evidence base does not yet justify widespread SBIRT in this setting [6]. This review will consider the nature of unhealthy alcohol use in the general hospital, review means for detecting unhealthy use and categorizing severity, consider the evidence on the effectiveness of SBIRT in the hospital setting, briefly review acute treatment issues, and discuss factors affecting the implementation of SBIRT into general hospital workflows. The goal is to provide an overview of the

\footnotetext{
* Correspondence: ss243@buffalo.edu

Division of General Internal Medicine, University at Buffalo State University of New York, Buffalo, NY, USA
}

field that will aid hospital-based clinicians and administrators in their consideration of policies and procedures that will yield the highest quality care for their patients. In this regard, the impact of detecting and treating unhealthy alcohol use is one of many important health care issues that must be evaluated.

\section{Unhealthy alcohol use in the hospital}

Unhealthy alcohol use is an umbrella term encompassing any pattern of alcohol use that increases risk for or causes physical problems [7]. At the lower end of severity, unhealthy use is often operationalized as drinking in excess of health-related guidelines. In the US, the National Institute on Alcohol Abuse and Alcoholism defines this as more than one drink daily, more than 7 drinks weekly, or exceeding 3 drinks on a given day for women and for men $\geq 65$, and more than two drinks daily, more than 14 drinks weekly, or exceeding 4 drinks on a given day for men $<65$ [8]. Pertinent to these guidelines, a standard drink is defined as a volume of beverage containing 14 grams of alcohol. This corresponds to a $12-\mathrm{oz}$ ( $355 \mathrm{ml}$ ) beer containing $5 \%$ alcohol by volume, 5 oz. (148 ml) of wine containing 12\% alcohol, or $1.5 \mathrm{oz}$. (44 ml) of spirits containing $40 \%$ alcohol. While modestly exceeding these limits in a sustained 
manner is unlikely to cause traditionally alcohol-related harms, this pattern is variably associated with increased morbidity in the long term relative to lighter drinking [9-11]. At the higher end of severity is the daily or frequent consumption of large amounts of alcohol, with sharply increased risks for alcohol dependence, cirrhosis, upper airway and gastrointestinal tract cancers, dementia, and other highly morbid conditions.

The prevalence of unhealthy use among hospital inpatients will depend on characteristics of hospitals and the populations they serve [12]. However, a systematic review of screening studies suggested an overall average of about $17 \%$ will self-report unhealthy use [13], with a 3fold increase in men relative to women. This summary estimate is less than the prevalence in the general adult population [8]. However, because unhealthy alcohol use is most common in younger males, unhealthy use is felt to increase the risk for hospitalization after accounting for age and gender [14]. Among general hospital patients who do consume alcohol, regardless of the presence of unhealthy use, about one-quarter will have an alcohol use disorder, which is much higher relative to current drinkers in the general population [15-17]. In addition to their physical health problems, relative to the nonhospitalized alcohol dependent population, hospitalized alcohol-dependent individuals have a higher prevalence of polysubstance use and mental health comorbidities [18]. Thus, while inpatient clinicians provide care for patients representing the broad spectrum of unhealthy alcohol use, there is a particularly high prevalence of complex alcohol dependent patients. Because brief intervention is most effective in patients with less severe unhealthy alcohol use, this has profound implications for the effectiveness of hospital-based SBIRT. Of note, despite these increased health risks, the evidence on severe unhealthy alcohol use and early hospital readmission is mixed $[19,20]$, and may depend on concurrent abuse of other drugs.

\section{Detecting and categorizing the severity of unhealthy alcohol use}

The process of detecting and categorizing the severity of unhealthy alcohol use focuses on two aspects of alcohol involvement. Firstly, the amount of alcohol consumed must be quantified, and this will determine the presence or absence of unhealthy use. Secondly, alcohol-related consequences should be assessed to determine the presence of an alcohol use disorder.

\section{Assessment for unhealthy alcohol use}

Alcohol use is often recorded in a hospital admission history \& physical by the frequency with which a certain amount of alcohol is consumed. With this method, alcohol use should be estimated in an unambiguous manner using the definition of a standard drink, and aids are available to assist clinicians and their patients in estimating alcohol consumption [8]. Rather than non-standardized questioning to characterize alcohol use, a number of short instruments have been evaluated [21], and their brevity should facilitate standardized screening in the hospital. Some of these tools are listed in Table 1, including the AUDIT-C [22-24], quantity-frequency items [24,25], and heavy drinking day question [26,27], any of which should target past-year drinking. The estimates shown in the table were derived from primary care samples [24,27], and could differ to some extent in hospitalized patients. None of the instruments are perfectly specific, and positive results should trigger additional inquiry to characterize drinking and confirm unhealthy alcohol use.

An added complexity of assessing for unhealthy alcohol use in hospitalized patients is illness severity, which may prohibit obtaining information directly from the patient. In such circumstances the presence of unhealthy alcohol use can often be estimated from past medical records or surrogate reporters. When alcohol-related disease is suspected blood alcohol levels can be helpful if heavy drinking occurred in the past 8 to 12 hours (an average elimination is roughly one drink per hour). Gammaglutamyltransferase also has some utility, but will be less specific for chronic heavy drinking in medical settings [28]. Carbohydrate-deficient transferrin, another biomarker for chronic heavy drinking, has been shown to predict adverse perioperative events [29], but is limited by modest sensitivity. In addition, results may not be available for several days, limiting use for decision-making in the hospital. Newer alcohol consumption biomarkers that require ethanol for their synthesis (e.g., urine ethyl glucuronide [30], blood phosphatidylethanol [31]) are a research focus and clearly have potential clinical utility [32-39]). In general however, pending the development of costeffective, widely-available assays at the point of care, use of these newer biomarkers in risk-stratifying for alcohol problems at the time of hospitalization is not yet feasible in most locations.

\section{Assessment for alcohol use disorders in patients with unhealthy use}

In patients with unhealthy alcohol use, characterization of severity requires an assessment of recent alcoholrelated problems, which will often satisfy the criteria for an alcohol use disorder in hospitalized patients [16]. A number of screening instruments for alcohol use disorder have been developed, and some are listed in Table 2 [21,40].

Importantly, as for any ordinal screening instruments, different cutoff scores will result in a tradeoff between sensitivity and specificity. In addition, relatively low cutoff scores on an instrument that assesses both the 
Table 1 Selected findings on brief screening tools for unhealthy alcohol use

\begin{tabular}{|c|c|c|c|c|}
\hline Screening tool & Positive result & $\begin{array}{l}\text { Sensitivity } \\
(95 \% \mathrm{Cl})\end{array}$ & $\begin{array}{l}\text { Specificity } \\
(95 \% \mathrm{Cl})\end{array}$ & Study Populations \\
\hline AUDIT-C & $\geq 4$ (men) & 86 (80-92) men & 89 (85-93) men & Primary care [24] \\
\hline$(3$ items)* & $\geq 3$ (women) & 73 (66-79) women & 91 (89-93) women & \\
\hline Quantity-Frequency & Exceeding recommended & 88 (83-94) men & 84 (80-89) men & Primary care [24] \\
\hline$(3$ items)* & drinking limits & 68 (61-75) women & 91 (89-93) women & \\
\hline Heavy-drinking day & \multirow{2}{*}{$\begin{array}{c}\text { Any heavy days } \\
\text { ( } \geq 4 \text { drinks women, } \geq 5 \text { drinks men) }\end{array}$} & 83 (71-90) men & $72(61-81)$ men & Primary care [27] \\
\hline past year (1 item) & & 81 (64-91) women & 84 (76-89) women & \\
\hline
\end{tabular}

*The AUDIT-C and quantity-frequency items were identical, with different interpretations of a positive result.

magnitude of drinking and alcohol-related consequences can be used to screen for unhealthy alcohol use and alcohol use disorders (e.g., as with the AUDIT [41]). Ultimately however, a diagnosis of an alcohol use disorder should be based on an assessment of established criteria.

The American Psychiatric Association (Diagnostic and Statistical Manual/DSM) and World Health Organization (International Classification of Disease/ICD) have developed criteria for a diagnosis of current alcohol dependence that substantially overlap, and require the presence of at least 3 of the diagnostic criteria during the past 12 months (or cooccurring more distantly for alcohol dependence in remission). The current DSM-IV criteria for dependence and abuse are listed in Table 3. Importantly, due to evidence that alcohol problems exist on a continuum rather than sharply defined categories, the upcoming revision of the DSM in 2013 (DSM-V) will controversially do away with the terms "abuse" and "dependence", and will have only "alcohol use disorder" [42,43]. Individuals satisfying 2 or 3 of the 11 criteria will be classified as having "moderate" alcohol use disorder, and those meeting 4 or more criteria will be classified with "severe" alcohol use disorder. This DSM-V reclassification may cause some initial confusion, but the concept of a single disorder that varies in severity will likely be a welcome change for many hospital-based clinicians.

\section{Treatment for unhealthy alcohol use}

\section{Treatment for non-dependent unhealthy alcohol use}

After initial screening and clinical assessment, patients with unhealthy alcohol use will have been categorized as having or not having an alcohol use disorder. In the latter, the clinical effort should be aimed at drinking reduction to levels that are unlikely to contribute to health problems. To accomplish this, the evidence, while mixed, generally favors a modest effect of brief interventions during hospitalization. A meta-analysis [44] of 4 randomized controlled trials (one in trauma patients did not exclude dependence, two excluded dependence, and one excluded patients with alcohol-related physical problems) concluded that brief intervention for unhealthy drinkers reduced alcohol consumption by an average of approximately 5 drinks/week 6 months post-intervention. Exclusion of the trauma-based trial due to unblinded outcome assessment reduced the magnitude and statistical significance of this estimate. Reported alcohol use at one year was synthesized for 4 other studies (3 with variable exclusion of patients with alcohol use disorders) and, although there was roughly a 2 drink per week reduction in the intervention groups, this was not statistically significant relative to controls. Importantly, while the evidence base for outcomes other than alcohol use is relatively underdeveloped, this meta-analysis found evidence that brief intervention was associated with decreased mortality at one year. In addition, a US study of trauma patients reported a $47 \%$ reduction in recurrent trauma over the 3 years following receipt of brief intervention [45].

Overall, the evidence tends to favor brief intervention for hospitalized patients with less severe unhealthy alcohol use. A number of different strategies have been studied, but brief intervention in the hospital should

Table 2 Selected findings on brief screening tools for alcohol use disorders

\begin{tabular}{lcccc}
\hline Instrument & Positive result & Sensitivity & Specificity & Study populations \\
\hline AUDIT & $\geq 8$ & Range & Range & Systematic review of primary care studies [21] \\
$(10$ items)* & 61 to 96 & 85 to 96 & \\
CAGE & $\geq 2$ & Range & Range & Systematic review of primary care studies [21] \\
$(4$ items $)$ & 77 to 94 & 79 to 97 & Emergency department patients [40] \\
RAPS4 & $\geq 1$ & 93 & 87 & \\
$(4$ items $)$ & & &
\end{tabular}

*AUDIT includes the AUDIT-C and can be used to screen for unhealthy alcohol use. Similarly, screens in Table 1 can be combined with screens in Table 2 to jointly screen for unhealthy alcohol use and alcohol use disorders. 
Table 3 American Psychiatric Association criteria for alcohol use disorders

\begin{tabular}{|c|c|c|}
\hline $\begin{array}{l}\text { DSM-IV Alcohol dependence } \\
\text { ( } \geq 3 \text { of the following) }\end{array}$ & $\begin{array}{l}\text { DSM-IV Alcohol abuse } \\
\text { ( } \geq 1 \text { of the following) }\end{array}$ & $\begin{array}{l}\text { DSM-V Alcohol use disorder } \\
(\geq 2 \text { of the following) }\end{array}$ \\
\hline - Tolerance & Continued drinking despite.... & - Tolerance \\
\hline • Withdrawal & & - Withdrawal \\
\hline - Repeatedly exceeding intended limits & $\begin{array}{l}\text { - Increased risk for } \\
\text { physical harm }\end{array}$ & - Repeatedly exceeding intended limits \\
\hline $\begin{array}{l}\text { - Spending a lot of time drinking or } \\
\text { recovering from alcohol effects }\end{array}$ & $\begin{array}{l}\text { - Trouble in important } \\
\text { relationships }\end{array}$ & $\begin{array}{l}\text { - Spending a lot of time drinking or } \\
\text { recovering from alcohol effects }\end{array}$ \\
\hline - Failed attempts to cut down or abstain & $\begin{array}{l}\text { - Failure to perform important } \\
\text { roles }\end{array}$ & - Failed attempts to cut down or abstain \\
\hline $\begin{array}{l}\text { - Continued drinking despite physical or psychological } \\
\text { problems }\end{array}$ & - Legal problems* & $\begin{array}{l}\text { - Continued drinking despite physical or psychological } \\
\text { problems }\end{array}$ \\
\hline \multirow[t]{5}{*}{$\begin{array}{l}\text { - Spending less time on important activities } \\
\text { due to drinking }\end{array}$} & & $\begin{array}{l}\text { - Spending less time on important } \\
\text { activities due to drinking }\end{array}$ \\
\hline & & - Increased risk for physical harm \\
\hline & & - Trouble in important relationships \\
\hline & & - Failure to perform important roles \\
\hline & & - Craving for alcohol* \\
\hline
\end{tabular}

*"Legal problems" will be dropped as an alcohol use disorder criterion, and "craving" will be added.

include at a minimum feedback about alcohol use (including associations with conditions the patient may have such as hypertension), advice to reduce consumption to safer levels, an explanation of why these limits are recommended, a non-confrontational inquiry to determine a patient's interest in reducing their drinking, and determination of a plan to achieve drinking goals [46]. This can be delivered by a variety of health care personnel $[44,47]$, which can lower the cost of brief intervention.

\section{Acute Treatment for alcohol use disorders (typically accompanied by frequent heavy drinking)}

The potential for acute complications renders the detection of alcohol use disorders and associated heavy drinking particularly important at the time of hospitalization. A number of informative reviews are available for guiding care $[7,48-50]$, and only a brief summary is provided here (Table 4). In patients with prior severe withdrawal or unstable medical disease, clinicians may wish to institute preventive measures for acute alcohol withdrawal with fixed dose benzodiazepines (e.g., chlordiazepoxide $50 \mathrm{mg}$ every 6 hours for 24 hours followed by $25 \mathrm{mg}$ every 6 hours for 48 hours) [48]. Patients must still be monitored for over-sedation or inadequate dosing. Active withdrawal can be managed with symptom-triggered or scheduled benzodiazepine dosing, with the former resulting in decreased benzodiazepine use and shorter treatment duration [51]. Several potential regimens are listed in Table 5 [49,51-53], and use of a shorter-acting benzodiazepine (e.g., lorazepam) will require a taper to prevent recurrent symptoms. Monitoring and dosing must be guided by a validated symptom scale such as the Clinical Institute Withdrawal Assessment for Alcoholrevised (CIWA-Ar) or somewhat shorter CIWA-AD [54-56] administered by trained personnel. Inappropriate selection of patients for symptom-triggered therapy has been reported, with the major reasons being inability to communicate (and thus assess all withdrawal symptoms), lack of heavy drinking in the days preceding hospitalization, and other causes of delirium [57]. Thus an accurate history is required and other causes of delirium must always be considered. For example, chronic heavy drinking suppresses the immune system [58,59], and clinicians must remain vigilant for infections such as pneumonia or sepsis. Other causes of delirium (e.g., hypoxia, stroke, effects of drugs other than alcohol, etc.) may also need to be ruled out depending on the clinical circumstances.

Initial treatment of severe withdrawal may require intravenous benzodiazepines (e.g., 2 to $4 \mathrm{mg}$ of lorazepam or 5 to $10 \mathrm{mg}$ of diazepam) and additional dosing as needed to control symptoms. Usually benzodiazepines alone are sufficient, and a strong evidence base supports their use [60]. The rare patient with severe withdrawal who fails benzodiazepine treatment will require intensive monitoring and treatment with barbiturates or propofol [49]. Phenobarbital is most frequently used in this circumstance, with 30 mg having roughly equivalent effects on withdrawal symptoms as $2 \mathrm{mg}$ lorazepam, $25 \mathrm{mg}$ chlordiazepoxide, or 10 mg diazepam [53]. Some centers with expertise in alcohol withdrawal treatment use anticonvulsants (e.g., carbamazepine, gabapentin) as a primary prophylaxis or treatment rather than benzodiazepines, but the evidence base 
Table 4 Immediate issues in the care of chronic heavy drinkers admitted to the hospital

\begin{tabular}{|c|c|}
\hline Clinical issue & Treatment \\
\hline \multirow[t]{2}{*}{ Assess risk for nutritional deficiency } & • Thiamine supplementation. \\
\hline & - Possibly folate and multivitamin supplement. \\
\hline \multirow{2}{*}{$\begin{array}{l}\text { Assess hydration status and electrolytes (risk for hypocalcemia and } \\
\text { hypomagnesemia with or without hypokalemia and } \\
\text { hypophosphatemia) }\end{array}$} & •IV or oral fluids. \\
\hline & - Oral or IV electrolyte replacement. \\
\hline \multirow[t]{2}{*}{ Risk for acute alcohol withdrawal } & $\begin{array}{l}\text { - Close observation with validated instrument or prophylactic } \\
\text { benzodiazepine, particularly in those with previous withdrawals or history } \\
\text { of severe withdrawal (delirium tremens or seizure). }\end{array}$ \\
\hline & - Prophylaxis still requires close observation for over or under-sedation. \\
\hline \multirow[t]{6}{*}{ Active alcohol withdrawal } & - Symptom-triggered or scheduled benzodiazepine. \\
\hline & $\begin{array}{l}\text { - Close observation with validated instrument with either symptom- } \\
\text { triggered or scheduled dosing. }\end{array}$ \\
\hline & $\begin{array}{l}\text { - Alternate medication (e.g., phenobarbital) in rare event that } \\
\text { benzodiazepine is unsuccessful at controlling agitation. }\end{array}$ \\
\hline & $\begin{array}{l}\text { - Possible beta blocker or clonidine for autonomic manifestations if } \\
\text { benzodiazepine alone is insufficient. }\end{array}$ \\
\hline & - Possible haloperidol if benzodiazepine alone is insufficient for delirium. \\
\hline & - Consider other causes of delirium. \\
\hline
\end{tabular}

for justifying clinical recommendations is currently underdeveloped. In particular, anticonvulsants have not been shown to reduce the incidence of alcohol withdrawal seizure or delirium tremens [61]. The use of intravenous alcohol infusions continues in some locations [62], mainly in surgical specialties, due to some surgeons' familiarity and comfort with this treatment. This approach has been discouraged due to potential toxicity (remembering that firstpass metabolism can be substantial in chronic heavy drinkers and is bypassed by this route), and evidence shows that this approach is at best no more efficacious for prophylaxis than benzodiazepines [63], and may have a high failure rate $[64,65]$.

\section{Pre-operative assessment for patients with an alcohol use disorder}

Chronic heavy drinking (e.g., averaging at least 50 to 60 grams of alcohol per day or usually exceeding daily limits) increases perioperative morbidity due to increased risks for acute withdrawal syndrome, pneumonia and ARDS, wound infections, bleeding, myocardial dysfunction, and enhanced stress responses $[59,66]$. Thus pre-operative detection should trigger efforts at detoxification and achieving several weeks of abstinence before elective procedures. For the more likely emergent procedures in hospitalized patients, parenteral thiamine, electrolyte replacement, and close monitoring and treatment for post-operative withdrawal are important components of care, and causes of delirium other than withdrawal should be considered as they would be for patients who are not heavy drinkers. Prevention of acute withdrawal with benzodiazepines is an important consideration in this population [67], and perioperative morphine may reduce post-operative pneumonia by ameliorating neuroendocrine and immune imbalances induced by chronic heavy drinking and peri-operative abstinence [68]. Much of the perioperative management will naturally be directed by the anesthesiologist and surgeon, and any consulting physicians should make certain that these providers are aware of the patient's heavy drinking. Of

Table 5 Examples of symptom-triggered regimens for alcohol withdrawal* $\dagger$

\begin{tabular}{|c|c|c|}
\hline Initial oral medication dose & Frequency & Medication half-life \\
\hline Diazepam 10 to $20 \mathrm{mg}$ if CIWA-Ar $\geq 8$ to 10 & $\begin{array}{l}\text { Repeat same dose hourly until } \\
\text { CIWA-Ar }<10\end{array}$ & $\begin{array}{l}\text { Long half-life may provide smoother withdrawal, but } \\
\text { may accumulate in elderly or those with liver disease. }\end{array}$ \\
\hline Chlordiazepoxide 50 mg if CIWA-Ar $>9$ & Repeat 50 mg hourly until CIWA-Ar $<10$ & $\begin{array}{l}\text { Intermediate half-life may provide smoother withdrawal } \\
\text { than lorazepam. }\end{array}$ \\
\hline Lorazepam 2 to $4 \mathrm{mg}$ if CIWA-Ar $\geq 8$ to 10 & $\begin{array}{l}\text { Repeat same dose hourly until } \\
\text { CIWA-Ar }<10\end{array}$ & $\begin{array}{l}\text { Short half-life may increase withdrawal symptoms between } \\
\text { doses. May be better tolerated in elderly and liver disease } \\
\text { patients. }\end{array}$ \\
\hline
\end{tabular}

*Fixed dose regimens generally consist of the same dose administered every 6 hours for 24 hours followed by half the initial dose every 6 hours for 48 hours. Close monitoring is still critical as adjustments in dose, frequency, and length of taper depend on clinical response.

tDetailed descriptions are found in citations 48 and 53. 
note, inappropriate use of symptom-triggered therapy for withdrawal has been observed in surgical patients [57]. It is equally important to communicate to all providers when a known heavy drinker has passed the time when initial manifestations of acute alcohol withdrawal would be expected (within 2 to 3 days of the last drink).

\section{Additional pre-discharge treatment considerations for patients with an alcohol use disorder}

Some research suggests hospitalization has the potential to facilitate treatment for alcohol use disorders by increasing recognition of the need to reduce drinking and intent to do so [69-72]. Despite this, brief interventions are unlikely to be effective at reducing drinking for hospitalized patients with alcohol dependence [73], but factors including avoidance of heavily drinking friends and engaging in alcohol treatment after hospitalization predict drinking reduction [71]. Thus referral for outpatient treatment should be pursued and integrated into brief intervention (i.e., SBIRT), but, even among research participants, overall compliance with referral is modest $[73,74]$. Brief intervention may be more effective in enhancing referral for women and younger adults [75]. Some evidence suggests that peer-involvement from volunteer Alcoholics Anonymous members as a supplement to brief intervention can increase treatment initiation and abstinence following hospitalization [76].

Following hospital discharge, integrated outpatient treatment (i.e., post-discharge care for alcoholism and medical conditions with the same healthcare provider) may be effective under ideal conditions [77,78]. A related approach involves a chronic disease management strategy in primary care with as-needed addiction specialist support, which may improve the quality of outpatient care and facilitate recovery $[79,80]$. Thus it is reasonable to refer patients to this mode of primary care if it exists locally.

Other potential interventions prior to discharge must be extrapolated from studies in treatment-seeking alcohol-dependent populations or treatment strategies implemented for other chronic medical and psychiatric conditions. Taking advantage of findings in the alcoholism pharmacotherapy field that show modest efficacy for several medications coupled with brief counseling strategies [81,82], an approach for alcohol dependent inpatients might include brief interventions and initiation of pharmacotherapy during the hospitalization. Several potential medications are listed in Table 6, together with a selection of their generally small effect sizes [83-87]. With the exception of disulfiram, medications for relapse prevention target brain receptors thought to be involved in relapse, including subsets of opioidergic, serotenergic, glutamatergic, and dopaminergic receptors [88], and complete abstinence may not be realized. As in the treatment of other conditions such as hypertension, reduced post-hospitalization drinking due to medication use may be considered a successful albeit partial response, even if the ultimate goal is abstinence. However, with the possible exception of transitional clinics following hospital discharge, continuation of medication will mainly be in the hands of ambulatory clinicians.

\section{Unhealthy alcohol use and the joint commission}

An impetus for a standardized approach to SBIRT for unhealthy alcohol use, is the recent inclusion by JCAHO of SBIRT as a quality care measure for hospitalized patients [5], and these recommendations have been summarized [6]. In brief, JCAHO has recommended screening for unhealthy use in all patients, brief intervention for patients with unhealthy use, in-hospital treatment or referral for alcohol use disorders, and consideration of medications for alcohol dependence treatment. Performance of these tasks would be measured by self-reported outcomes through phone contact within 2 weeks of discharge.

This JCAHO initiative is grounded in the recognition that unhealthy alcohol use and other drug use is a major determinant of health in hospitalized patients, but has been criticized due to insufficient evidence on the overall effectiveness of SBIRT among general hospital inpatients [6]. In that regard, the JCAHO quality initiative extends beyond the evidence, but represents an attempt to integrate research findings into medical care. This intent must be applauded, and should be used as a springboard to further develop methods that will improve patient outcomes following an index hospitalization. The more severe nature of unhealthy alcohol use in the hospital, the process of SBIRT, and the intended outcomes should drive the research agenda. Some thoughts in this regard are listed in Table 7, which is not meant to be exhaustive. Research efforts must be geared toward generic processes of care and quality assessment, as the intent will be to improve patient outcomes in settings where personnel with unique interests in this field are not always present.

\section{Implementation barriers and facilitators}

In general, major barriers to incorporation of evidencebased care include organizational leadership, work capacity, training, ongoing support, and others [89], and SBIRT is no exception. A systematic review of qualitative data from 47 studies [90] identified major SBIRTimplementation barriers to be limited resources, training, support of management, and workload. Most results were from primary-care-based studies, but, consistent with these findings, critical components of implementing and sustaining SBIRT at a rural hospital in Australia included the support of hospital management and a dedicated project worker [91]. Similar issues were also identified for nursing-delivered SBIRT, with the addition 
Table 6 Select Effects of Medications on Drinking Outcomes

\begin{tabular}{|c|c|c|c|c|}
\hline Medication & Drinking Outcome & $\begin{array}{c}\text { Effect estimate } \\
\text { (95\% Cl or } p \text {-value) }\end{array}$ & Source & Factors Influencing Medication Choice \\
\hline \multirow[t]{2}{*}{ Naltrexone } & \multirow{2}{*}{$\begin{array}{l}\text { Heavy drinking day } \\
\text { ( } \geq 60 \text { grams alcohol) }\end{array}$} & Relative risk 0.83 & Meta-analysis of 50 & \multirow{2}{*}{$\begin{array}{l}\text { Avoid in patients with opioid abuse } \\
\text { or use; caution in liver disease and } \\
\text { advanced kidney disease }\end{array}$} \\
\hline & & $(0.76-0.90)$ & $\begin{array}{l}\text { randomized controlled } \\
\text { trial (RCT's) [87] }\end{array}$ & \\
\hline \multirow[t]{2}{*}{ Acamprosate } & \multirow[t]{2}{*}{ Any drinking } & Relative risk 0.86 & Meta-analysis of 24 & \multirow{2}{*}{$\begin{array}{l}\text { Avoid with advanced kidney disease } \\
\text { (e.g., creatinine clearance }<30 \mathrm{ml} / \mathrm{min} \text { ) }\end{array}$} \\
\hline & & $(0.81-0.91)$ & RCT's [86] & \\
\hline Disulfiram & Any drinking & $\begin{array}{l}\text { Slight majority of trials } \\
\text { found improved } \\
\text { abstinence. }\end{array}$ & Review of 11 RCT's [85] & $\begin{array}{l}\text { Avoid if alcohol-disulfiram reaction } \\
\text { medically dangerous; number of medical } \\
\text { conditions associated with accidental reaction; } \\
\text { avoidance of alcohol-containing products }\end{array}$ \\
\hline \multirow[t]{2}{*}{ Topiramate* } & \multirow[t]{2}{*}{$\%$ heavy drinking days } & $8.4 \%$ reduction & Multicenter RCT [83] & \multirow{2}{*}{$\begin{array}{l}\text { Caution with advanced liver or kidney disease } \\
\text { risk for metabolic acidosis with predisposing } \\
\text { conditions; avoid abrupt discontinuation }\end{array}$} \\
\hline & & $(3.1-13.8)$ & & \\
\hline Ondansetron* & $\begin{array}{l}\text { Average number of } \\
\text { drinks on days alcohol } \\
\text { was consumed }\end{array}$ & $\begin{array}{l}\text { If alcoholism onset before } \\
\text { age } 25,4.28 \text { relative to } \\
6.9 \text { in placebo }(p=0.004)\end{array}$ & $\mathrm{RCT}[84]$ & $\begin{array}{l}\text { Not shown to be beneficial for later-onset } \\
\text { alcohol dependence; may prolong QT interval }\end{array}$ \\
\hline
\end{tabular}

*Not FDA-approved for treating alcohol dependence.

of concerns over limited interdisciplinary collaboration about alcohol problems, compatibility with the acute care nursing role, lack of privacy, and concerns about patient attitudes [92]. This latter issue was also identified in a previous hospital-based study on SBIRT [93]. Regarding training needs, SBIRT training programs have been shown to increase provider comfort in assessing alcohol problems and have increased utilization of SBIRT [94], and on-line instructional programs are available to enhance dissemination (e.g., http://medicine.yale. edu/sbirt/index.aspx; http://www.bu.edu/bniart/sbirt-in- health-care/sbirt-educational-materials/sbirt-videos/). An additional barrier is the lack of an unambiguous tool for monitoring the quality of SBIRT, which ideally should include assessment of core brief intervention components rather than non-specific provider or patient report of alcohol counseling [6,95]. Interestingly, implementation of a performance measure and electronic reminders were each associated with an increase in the receipt of brief intervention in outpatient VA settings [96], and this type of strategy has the potential to enhance SBIRT performance in the hospital [97].

Table 7 Potential research topics relevant to patient care and JCAHO quality measures

\begin{tabular}{|c|c|}
\hline Topic & Potential research foci \\
\hline \multirow[t]{7}{*}{ Screening and assessment } & -Is there reason to use more than a single heavy drinking day question to screen for unhealthy alcohol use? \\
\hline & -Is there a better strategy than screening all admissions? \\
\hline & •How should screening be integrated with electronic work flows? \\
\hline & -What is the role of newer alcohol consumption biomarkers? \\
\hline & -What is the optimal assessment method in the hospital? \\
\hline & $\begin{array}{l}\text {-What training will hospital-based clinicians require to enhance their skills and confidence in diagnosing } \\
\text { alcohol use disorders? }\end{array}$ \\
\hline & •How do patients feel about assessment during hospitalization? \\
\hline \multirow[t]{6}{*}{ Treatment } & -What patients are most likely to respond to brief intervention? \\
\hline & •How can the beneficial effects of brief intervention on alcohol use be increased? \\
\hline & •How do we enhance the success of referral? \\
\hline & -Does pharmacotherapy for relapse prevention work in this population? \\
\hline & -What is the role for joint detection and treatment of other drug and mental health co-morbidities? \\
\hline & -Can computerized support enhance treatment? \\
\hline \multirow[t]{3}{*}{ Measuring performance } & $\begin{array}{l}\text {-What are the effects of brief intervention on other outcomes such as progression of alcohol problems and } \\
\text { hospital readmission? }\end{array}$ \\
\hline & -What are the most pertinent patient-centered outcomes? \\
\hline & -What is the optimal method for assessing the quality of hospital-based SBIRT? \\
\hline
\end{tabular}




\section{Conclusions}

Unhealthy alcohol use is common in hospitalized patients, with a high prevalence of severe alcohol problems among those with unhealthy use. Detection should include the use of a validated screening instrument to determine the presence of unhealthy use, and assessment of alcohol-related consequences in patients with positive screening results to categorize the severity of unhealthy use. Based on current evidence, patients without an alcohol use disorder should receive a brief intervention to target reduced drinking. Acute care issues for patients with alcohol use disorders have been well described and are standards of care. Additional research is needed to guide discharge planning for inpatients with an alcohol use disorder, but management should include referral to outpatient addiction treatment if available, consideration of medications to prevent a return to heavy drinking, and explicit follow-up on alcohol use in the ambulatory medical setting. JCAHO has advanced SBIRT for unhealthy alcohol use as a quality measure, and barriers to implementation are mainly generic factors rather than specific to SBIRT. Continued research is needed across the spectrum of unhealthy alcohol use to further demonstrate the benefits of hospital-based SBIRT, refine the process, and improve care for hospitalized patients.

\section{Competing interests}

The authors declare that they have no competing interests.

\section{Authors' contributions}

RM and SHS each reviewed the literature and participated in drafting the manuscript. Both authors read and approved the final manuscript.

Received: 18 December 2012 Accepted: 24 May 2013

Published: 5 June 2013

\section{References}

1. Bouchery EE, Harwood HJ, Sacks JJ, Simon CJ, Brewer RD: Economic costs of excessive alcohol consumption in the U.S., 2006. Am J Prev Med 2011, 41:516-524.

2. Global status report on alcohol. Geneva: World Health Organization; 2004 Available at http://www.who.int/substance_abuse/publications/ global_status_report_2004_overview.pdf.

3. US Preventive Services Taskforce: Screening and behavioral counseling interventions in primary care to reduce alcohol misuse: recommendation statement. Ann Intern Med 2004, 140:554-556.

4. Kaner E: NICE work if you can get it: Development of national guidance incorporating screening and brief intervention to prevent hazardous and harmful drinking in England. Drug Alcohol Rev 2010, 29:589-595.

5. Specifications manual for national hospital inpatient quality measures. [www.jointcommission.org/specifications_manual_for_national_hospital_ inpatient_quality_measures].

6. Saitz R: Candidate performance measures for screening for, assessing, and treating unhealthy substance use in hospitals: advocacy or evidence-based practice? Ann Intern Med 2010, 153:40-43.

7. Saitz R: Clinical practice. Unhealthy alcohol use. N Engl J Med 2005, 352:596-607.

8. National Institute on Alcohol Abuse and Alcoholism: Helping patients who drink too much: A clinician's guide. US Department of Health and Human Services; 2007

9. Jin M, Cai S, Guo J, Zhu Y, Li M, Yu Y, Zhang S, Chen K: Alcohol drinking and all cancer mortality: a meta-analysis. Ann Onco 2012, 24:807-816.
10. Patra J, Taylor B, Irving H, Roerecke M, Baliunas D, Mohapatra S, Rehm J: Alcohol consumption and the risk of morbidity and mortality for different stroke types-a systematic review and meta-analysis. BMC Publ Health 2010, 10:258.

11. Costanzo S, Di Castelnuovo A, Donati MB, lacoviello L, de Gaetano G: Alcohol consumption and mortality in patients with cardiovascular disease: a meta-analysis. J Am Coll Cardiol 2010, 55:1339-1347.

12. Holt SR, Ramos J, Harma MA, Cabrera F, Louis-Ashby C, Dinh A, Tetrault JM, Fiellin DA: Prevalence of unhealthy substance use on teaching and hospitalist medical services: implications for education. Am J Addict 2012, 21:111-119.

13. Roche AM, Freeman T, Skinner N: From data to evidence, to action: findings from a systematic review of hospital screening studies for high risk alcohol consumption. Drug Alcohol Depend 2006, 83:1-14.

14. Chick J, Duffy JC, Lloyd GG, Ritson B: Medical admissions in men: the risk among drinkers. Lancet 1986, 2:1380-1383.

15. Smothers BA, Yahr HT, Ruhl CE: Detection of alcohol use disorders in general hospital admissions in the United States. Arch Intern Med 2004, 164:749-756.

16. Saitz R, Freedner N, Palfai TP, Horton NJ, Samet JH: The severity of unhealthy alcohol use in hospitalized medical patients. The spectrum is narrow. Journal of General Internal Medicine 2006, 21:381-385.

17. Freyer-Adam J, Coder B, Baumeister SE, Bischof G, Riedel J, Paatsch K, Wedler B, Rumpf HJ, John U, Hapke U: Brief alcohol intervention for general hospital inpatients: a randomized controlled trial. Drug Alcohol Depend 2008, 93:233-243.

18. Stewart SH: Alcoholics in acute medical settings have increased risk for other drug, mood, and personality disorders. Int J Psychiatry Med 2007, 37:59-67.

19. Walley AY, Paasche-Orlow M, Lee EC, Forsythe S, Chetty VK, Mitchell S, Jack BW: Acute care hospital utilization among medical inpatients discharged with a substance use disorder diagnosis. J Addict Med 2012, 6:50-56.

20. Jiang HJ, Wier LM: All cause hospital readmissions among non-elderly Medicaid patients, 2007. Agency for Healthcare Research and Quality 2010. HCUP Statistical Brief \#89. Available at http://www.hcup-us.ahrq.gov/reports/ statbriefs/sb89.jsp.

21. Fiellin DA, Reid MC, O'Connor PG: Screening for alcohol problems in primary care: a systematic review. Arch Intern Med 2000, 160:1977-1989.

22. Babor TF, de la Fuente JR, Saunders J, Grant M: AUDIT. The Alcohol Use Disorders Identification Test. Guidelines for use in primary health care. Geneva, Switzerland: World Health Organization; 1992.

23. Bush K, Kivlahan DR, McDonell MB, Fihn SD, Bradley KA: The Ambulatory Care Quality Improvement Project (ACQUIP): The AUDIT alcohol consumption questions (AUDIT-C): An effective brief screening test for problem drinking. Arch Intern Med 1998, 158:1789-1795.

24. Bradley KA, DeBenedetti AF, Volk RJ, Williams EC, Frank D, Kivlahan DR: AUDIT-C as a brief screen for alcohol misuse in primary care. Alcohol Clin Exp Res 2007, 31:1208-1217.

25. Friedmann PD, Saitz R, Gogineni A, Zhang JX, Stein MD: Validation of the screening strategy in the NIAAA "Physicians' Guide to Helping Patients with Alcohol Problems". J Stud Alcohol 2001, 62:234-238,

26. Williams $R$, Vinson DC: Validation of a single screening question for problem drinking. J Fam Pract 2001, 50:307-312.

27. Smith PC, Schmidt SM, Allensworth-Davies D, Saitz R: Primary care validation of a single-question alcohol screening test. I Gen Intern Med 2009, 24:783-788

28. Conigrave KM, Davies P, Haber P, Whitfield JB: Traditional markers of excessive alcohol use. Addiction 2003, 98(Suppl 2):31-43.

29. Spies CD, Kissner M, Neumann T, Blum S, Voigt C, Funk T, Runkel N, Pragst F: Elevated carbohydrate-deficient transferrin predicts prolonged intensive care unit stay in traumatized men. Alcohol Alcohol 1998, 33:661-669.

30. Wurst FM, Skipper GE, Weinmann W: Ethyl glucuronide-the direct ethanol metabolite on the threshold from science to routine use. Addiction 2003, 98(Suppl 2):51-61.

31. Varga A, Hansson P, Lundqvist C, Alling C: Phosphatidylethanol in blood as a marker of ethanol consumption in healthy volunteers: comparison with other markers. Alcohol Clin Exp Res 1998, 22:1832-1837.

32. Erim Y, Bottcher M, Dahmen U, Beck O, Broelsch CE, Helander A: Urinary ethyl glucuronide testing detects alcohol consumption in alcoholic liver disease patients awaiting liver transplantation. Liver Transp/ 2007, 13:757-761. 
33. Skipper GE, Weinmann W, Thierauf A, Schaefer P, Wiesbeck G, Allen JP, Miller M, Wurst FM: Ethyl glucuronide: a biomarker to identify alcohol use by health professionals recovering from substance use disorders. Alcohol Alcohol 2004, 39:445-449.

34. Staufer $\mathrm{K}$, Andresen $H$, Vettorazzi E, Tobias N, Nashan B, Sterneck M: Urinary ethyl glucuronide as a novel screening tool in patients pre and post liver transplantation improves detection of alcohol consumption. Hepatology 2011, 54:1640-1649.

35. Stewart SH, Koch DG, Burgess DM, Willner IR, Reuben A: Sensitivity and specificity of urinary ethyl glucuronide and ethyl sulfate in liver disease patients. Alcoholism: Clinical \& Experimental Research in press.

36. Hansson P, Caron M, Johnson G, Gustavsson L, Alling C: Blood phosphatidylethanol as a marker of alcohol abuse: levels in alcoholic males during withdrawal. Alcohol Clin Exp Res 1997, 21:108-110.

37. Hartmann S, Aradottir S, Graf M, Wiesbeck G, Lesch O, Ramskogler K, Wolfersdorf M, Alling C, Wurst FM: Phosphatidylethanol as a sensitive and specific biomarker: comparison with gamma-glutamyl transpeptidase, mean corpuscular volume and carbohydrate-deficient transferrin. Addict Biol 2007, 12:81-84.

38. Stewart SH, Law TL, Randall PK, Newman R: Phosphatidylethanol and Alcohol Consumption in Reproductive Age Women. Alcohol Clin Exp Res 2010, 34:488-492.

39. Stewart SH, Reuben A, Brzezinski WA, Koch DG, Basile J, Randall PK, Miller PM: Preliminary evaluation of phosphatidylethanol and alcohol consumption in patients with liver disease and hypertension. Alcohol Alcohol 2009, 44:464-467

40. Cherpitel $\mathrm{CJ}$ : A brief screening instrument for problem drinking in the emergency room: the RAPS4. Rapid Alcohol Problems Screen. Journal of Studies on Alcohol 2000, 61:447-449.

41. Johnson JA, Lee A, Vinson D, Seale JP: Use of AUDIT-based measures to identify unhealthy alcohol use and alcohol dependence in primary care: a validation study. Alcohol Clin Exp Res 2013, 37(Suppl 1):E253-E259.

42. Schuckit MA: Editor's corner: editorial in reply to the comments of Griffith Edwards. J Stud Alcohol Drugs 2012, 73:521-522.

43. Hasin DS: Combining abuse and dependence in DSM-5. J Stud Alcohol Drugs 2012, 73:702-704.

44. McQueen J, Howe TE, Allan L, Mains D, Hardy V: Brief interventions for heavy alcohol users admitted to general hospital wards. Cochrane Database Syst Rev 2011:CD005191.

45. Gentilello LM, Rivara FP, Donovan DM, Jurkovich GJ, Daranciang E, Dunn CW, Villaveces A, Copass M, Ries RR: Alcohol interventions in a trauma center as a means of reducing the risk of injury recurrence. Ann Surg 1999, 230:473-480. discussion 480-473.

46. Bien TH, Miller WR, Tonigan JS: Brief interventions for alcohol problems: a review. Addiction 1993, 88:315-335.

47. Broyles LM, Rosenberger E, Hanusa BH, Kraemer KL, Gordon AJ: Hospitalized patients' acceptability of nurse-delivered screening, brief intervention, and referral to treatment. Alcohol Clin Exp Res 2012, 36:725-731.

48. Mayo-Smith MF: Pharmacological management of alcohol withdrawal. A meta-analysis and evidence-based practice guideline. American Society of Addiction Medicine Working Group on Pharmacological Management of Alcohol Withdrawal. JAMA 1997, 278:144-151.

49. Mayo-Smith MF, Beecher LH, Fischer TL, Gorelick DA, Guillaume JL, Hill A Jara G, Kasser C, Melbourne J: Management of alcohol withdrawal delirium. An evidence-based practice guideline. Archives of Internal Medicine 2004, 164:1405-1412.

50. Saitz R: Overview of Medical and Surgical Complications. In Principles of Addiction Medicine. Edited by Graham AW, Schultz TK, Mayo-Smith MF, Ries RK, Wilford BB, Chevy C, Chevy Chase MD. Chevy Chase, Maryland: American Society of Addiction Medicine; 2003:1027-1052.

51. Saitz R, Mayo-Smith MF, Roberts MS, Redmond HA, Bernard DR, Calkins DR Individualized treatment for alcohol withdrawal. A randomized doubleblind controlled trial. JAMA 1994, 272:519-523.

52. Spies CD, Otter HE, Huske B, Sinha P, Neumann T, Rettig J, Lenzenhuber E, Kox WJ, Sellers EM: Alcohol withdrawal severity is decreased by symptom-orientated adjusted bolus therapy in the ICU. Intensive Care Med 2003, 29:2230-2238.

53. Detoxification and substance abuse treatment. In Treatment improvement protocol 45. Edited by Miller NS, Kipnis SS. Rockville MD: Substance Abuse and Mental Health Services Administration. DHHS publication no; 2006. 064131. Available at http://www.ncbi.nlm.nih.gov/books/NBK64115/pdf/TOC.pdf.
54. Foy A, McKay S, Ling S, Bertram M, Sadler C: Clinical use of a shortened alcohol withdrawal scale in a general hospital. Intern Med J 2006, 36:150-154.

55. Sullivan JT, Sykora K, Schneiderman J, Naranjo CA, Sellers EM: Assessment of alcohol withdrawal: the revised clinical institute withdrawal assessment for alcohol scale (CIWA-Ar). Br J Addict 1989, 84:1353-1357.

56. Reoux JP, Oreskovich MR: A comparison of two versions of the clinical institute withdrawal assessment for alcohol: the CIWA-Ar and CIWA-AD. Am J Addict 2006, 15:85-93.

57. Hecksel KA, Bostwick JM, Jaeger TM, Cha SS: Inappropriate use of symptom-triggered therapy for alcohol withdrawal in the general hospital. Mayo Clin Proc 2008, 83:274-279.

58. Brown LA, Cook RT, Jerrells TR, Kolls JK, Nagy LE, Szabo G, Wands JR, Kovacs EJ: Acute and chronic alcohol abuse modulate immunity. Alcohol Clin Exp Res 2006, 30:1624-1631.

59. Spies CD, von Dossow $V$, Eggers $V$, Jetschmann G, El-Hilali R, Egert J, Fischer M, Schroder T, Hoflich C, Sinha P, et al: Altered cell-mediated immunity and increased postoperative infection rate in long-term alcoholic patients. Anesthesiology 2004, 100:1088-1100.

60. Amato L, Minozzi S, Vecchi S, Davoli M: Benzodiazepines for alcohol withdrawal. Cochrane Database Syst Rev 2010:CD005063.

61. Minozzi S, Amato L, Vecchi S, Davoli M: Anticonvulsants for alcohol withdrawal. Cochrane Database Syst Rev 2010:CD005064.

62. Blondell RD, Dodds HN, Blondell MN, Looney SW, Smoger SH, Sexton LK, Wieland LS, Swift RM: Ethanol in formularies of US teaching hospitals. JAMA 2003, 289:552

63. Weinberg JA, Magnotti LJ, Fischer PE, Edwards NM, Schroeppel T, Fabian TC, Croce MA: Comparison of intravenous ethanol versus diazepam for alcohol withdrawal prophylaxis in the trauma ICU: results of a randomized trial. J Trauma 2008, 64:99-104.

64. Eggers V, Tio J, Neumann T, Pragst F, Muller C, Schmidt LG, Kox WJ, Spies CD: Blood alcohol concentration for monitoring ethanol treatment to prevent alcohol withdrawal in the intensive care unit. Intensive Care Med 2002, 28:1475-1482.

65. Hodges B, Mazur JE: Intravenous ethanol for the treatment of alcohol withdrawal syndrome in critically ill patients. Pharmacotherapy 2004 24:1578-1585

66. Tonnesen $\mathrm{H}$, Kehlet $\mathrm{H}$ : Preoperative alcoholism and postoperative morbidity. Br J Surg 1999, 86:869-874

67. Spies CD, Rommelspacher $\mathrm{H}$ : Alcohol withdrawal in the surgical patient: Prevention and treatment. Anesth Analg 1999, 88:946-954.

68. Spies C, Eggers V, Szabo G, Lau A, von Dossow V, Schoenfeld H, Althoff H, Hegenscheid K, Bohm B, Schroeder T, et al: Intervention at the level of the neuroendocrine-immune axis and postoperative pneumonia rate in long-term alcoholics. Am J Respir Crit Care Med 2006, 174:408-414.

69. Stewart SH, Connors GJ: Interest in pharmacotherapy and primary care alcoholism treatment among medically hospitalized, alcohol dependent patients. J Addict Dis 2007, 26:63-69.

70. Stewart SH, Connors GJ: Perceived health status, alcohol-related problems, and readiness to change among medically hospitalized, alcohol-dependent patients. Journal of Hospital Medicine (Online) 2007, 2:372-377.

71. Bertholet $N$, Cheng DM, Palfai TP, Saitz R: Factors associated with favorable drinking outcome 12 months after hospitalization in a prospective cohort study of inpatients with unhealthy alcohol use. J Gen Intern Med 2010, 25:1024-1029.

72. Lau K, Freyer-Adam J, Gaertner B, Rumpf HJ, John U, Hapke U: Motivation to change risky drinking and motivation to seek help for alcohol risk drinking among general hospital inpatients with problem drinking and alcohol-related diseases. Gen Hosp Psychiatry 2010, 32:86-93.

73. Saitz R, Palfai TP, Cheng DM, Horton NJ, Freedner N, Dukes K, Kraemer KL, Roberts MS, Guerriero RT, Samet JH: Brief intervention for medical inpatients with unhealthy alcohol use: a randomized, controlled trial. Ann Intern Med 2007, 146:167-176.

74. Pecoraro A, Horton T, Ewen E, Becher J, Wright PA, Silverman B, McGraw P, Woody $G E$, et al: Early data from project engage: a program to identify and transition medically hospitalized patients into addictions treatment. Addict Sci Clin Pract 2012, 7:20.

75. Saitz R, Palfai TP, Cheng DM, Horton NJ, Dukes K, Kraemer KL, Roberts MS, Guerriero RT, Samet JH: Some medical inpatients with unhealthy alcohol use may benefit from brief intervention. J Stud Alcohol Drugs 2009, 70:426-435. 
76. Blondell RD, Looney SW, Northington AP, Lasch ME, Rhodes SB, McDaniels RL: Can recovering alcoholics help hospitalized patients with alcohol problems? J Fam Pract 2001, 50:447.

77. Willenbring ML, Olson $\mathrm{DH}$ : A randomized trial of integrated outpatient treatment for medically ill alcoholic men. Arch Intern Med 1999, 159:1946-1952.

78. Lieber CS, Weiss DG, Groszmann R, Paronetto F, Schenker S: I. Veterans Affairs Cooperative Study of polyenylphosphatidylcholine in alcoholic liver disease: effects on drinking behavior by nurse/physician teams. Alcoholism: Clinical. Experimental Research 2003, 27:1757-1764.

79. Chi FW, Parthasarathy S, Mertens JR, Weisner CM: Continuing care and long-term substance use outcomes in managed care: early evidence for a primary care-based model. Psychiatr Serv 2011, 62:1194-1200.

80. Kim TW, Saitz R, Cheng DM, Winter MR, Witas J, Samet JH: Initiation and engagement in chronic disease management care for substance dependence. Drug Alcohol Depend 2011, 115:80-86.

81. Anton RF, O'Malley SS, Ciraulo DA, Cisler RA, Couper D, Donovan DM, Gastfriend DR, Hosking JD, Johnson BA, LoCastro JS, et al: Combined pharmacotherapies and behavioral interventions for alcohol dependence: the COMBINE study: a randomized controlled trial. J Am Med Assoc 2006, 295:2003-2017.

82. Miller PM, Book SW, Stewart SH: Medical treatment of alcohol dependence: a systematic review. Int J Psychiatry Med 2011, 42:227-266.

83. Johnson BA, Rosenthal N, Capece JA, Wiegand F, Mao L, Beyers K, McKay A Ait-Daoud N, Anton RF, Ciraulo DA, et al: Topiramate for treating alcohol dependence: a randomized controlled trial. JAMA 2007, 298:1641-1651.

84. Johnson BA, Roache JD, Javors MA, DiClemente CC, Cloninger CR, Prihoda TJ, Bordnick PS, Ait-Daoud N, Hensler J: Ondansetron for reduction of drinking among biologically predisposed alcoholic patients: A randomized controlled trial. JAMA 2000, 284:963-971.

85. Jorgensen $\mathrm{CH}$, Pedersen $\mathrm{B}$, Tonnesen $\mathrm{H}$ : The efficacy of disulfiram for the treatment of alcohol use disorder. Alcohol Clin Exp Res 2011, 35:1749-1758

86. Rosner S, Hackl-Herrwerth A, Leucht S, Lehert P, Vecchi S, Soyka M: Acamprosate for alcohol dependence. Cochrane Database Syst Rev 2010: CD004332.

87. Rosner S, Hackl-Herrwerth A, Leucht S, Vecchi S, Srisurapanont M, Soyka M: Opioid antagonists for alcohol dependence. Cochrane Database Syst Rev 2010:CD001867.

88. Johnson BA: Medication treatment of different types of alcoholism. Am J Psychiatry 2010, 167:630-639.

89. Wiltsey Stirman S, Kimberly J, Cook N, Calloway A, Castro F, Charns M: The sustainability of new programs and innovations: a review of the empirical literature and recommendations for future research. Implement Sci 2012, 7:17.

90. Johnson M, Jackson R, Guillaume L, Meier P, Goyder E: Barriers and facilitators to implementing screening and brief intervention for alcohol misuse: a systematic review of qualitative evidence. J Public Health (Oxf) 2011, 33:412-421.

91. Fahy $P$, Croton $G$, Voogt S: Embedding routine alcohol screening and brief interventions in a rural general hospital. Drug Alcohol Rev 2011, 30:47-54.

92. Broyles LM, Rodriguez KL, Kraemer KL, Sevick MA, Price PA, Gordon AJ: A qualitative study of anticipated barriers and facilitators to the implementation of nurse-delivered alcohol screening, brief intervention, and referral to treatment for hospitalized patients in a Veterans Affairs medical center. Addict Sci Clin Pract 2012, 7:7

93. McManus S, Hipkins J, Haddad P, Guthrie E, Creed F: Implementing an effective intervention for problem drinkers on medical wards. Gen Hosp Psychiatry 2003, 25:332-337.

94. Bernstein E, Bernstein J, Feldman J, Fernandez W, Hagan M, Mitchell P, Safi C, Woolard R, Mello M, Baird J, et al: An evidence based alcohol screening, brief intervention and referral to treatment (SBIRT) curriculum for emergency department (ED) providers improves skills and utilization. Subst Abus 2007, 28:79-92.

95. Bradley KA, Williams EC, Achtmeyer CE, Hawkins EJ, Harris AH, Frey MS Craig T, Kivlahan DR: Measuring performance of brief alcohol counseling in medical settings:a review of the options and lessons from the Veterans Affairs (VA) health care system. Subst Abus 2007, 28:133-149.

96. Lapham GT, Achtmeyer CE, Williams EC, Hawkins EJ, Kivlahan DR, Bradley $K A$ : Increased documented brief alcohol interventions with a performance measure and electronic decision support. Medical Care 2012, 50:179-187.

97. Sahota N, Lloyd R, Ramakrishna A, Mackay JA, Prorok JC, Weise-Kelly L, Navarro T, Wilczynski NL, Haynes RB: Computerized clinical decision support systems for acute care management: a decision-maker -researcher partnership systematic review of effects on process of care and patient outcomes. Implement Sci 2011, 6:91.

doi:10.1186/1940-0640-8-11

Cite this article as: Makdissi and Stewart: Care for hospitalized patients with unhealthy alcohol use: a narrative review. Addiction Science \& Clinical Practice 2013 8:11.

\section{Submit your next manuscript to BioMed Central and take full advantage of:}

- Convenient online submission

- Thorough peer review

- No space constraints or color figure charges

- Immediate publication on acceptance

- Inclusion in PubMed, CAS, Scopus and Google Scholar

- Research which is freely available for redistribution 